ISSN. 2775-4324 (Online)

Journal of Physical Activity and Sports

Volume 2, Nomor 2, Agustus 2021, 204-207

\title{
PERBANDINGAN LATIHAN RESISTANCE DAN LADDER UNTUK MENINGKATKAN KECEPATAN LARI PEMAIN FUTSAL SMA N 3 PEMALANG
}

\author{
Liyalin Mubarok \\ ${ }^{1}$ Universitas PGRI Semarang, Jawa Tengah, Indonesia \\ E-mail: mubarokliyalin44@gmail.com
}

\begin{abstract}
This research is motivated by the physical condition of the running speed of the extracurricular futsal team of SMA Negeri 3 Pemalang which is not good, this can be seen from the many players who do not have a maximum running speed. This study aims to determine the effect of resistance band and ladder exercises in increasing running speed in futsal games and to find out which exercises are more effective. The research subjects sampled in the study were 16 students of SMA N 3 Pemalang who participated in futsal extracurricular activities which were divided into 2 groups, namely the first group of 8 resistance band exercises and the second group of 8 ladder exercises. Data collection was carried out with a 60-meter running speed test on the Cibelok soccer field. The research design used was a pre-test and post-test group, therefore, data collection was carried out during the pretest and posttest. Based on the calculation results, it was found that the increase in running speed with Resistance band training was $4.95 \%$, while with Ladder training it was $13.58 \%$. So that Ladder training is more effective to increase running speed. The conclusion of this study is that the Ladder training method is more effective and good in increasing the running speed of futsal extracurricular players at SMAN 3 Pemalang.
\end{abstract}

Keywords : Futsal, Running Speed, Resistance Band, Ladder

\begin{abstract}
Abstrak
Penelitian ini dilatarbelakangi oleh kondisi fisik kecepatan lari pada tim futsal ekstrakulikuluer SMA Negeri 3 Pemalang yang kurang baik, hal ini dilihat dari masih banyak pemain yang belum mempunyai kecepatan lari yang maksimal. Penelitian yang bertujuan untuk mengetahui pengaruh latihan resistance band dan ladder dalam meningkatkan kecepatan lari dalam permainan futsal dan akan diketahui latihan mana yang lebih efektif. Subyek penelitian yang dijadikan sampel dalam penelitian yaitu siswa SMA N 3 Pemalang yang mengikuti kegiatan ekstrakulikuler futsal sebanyak 16 orang yang dibagi menjadi 2 kelompok yaitu kelompok pertama latihan resistance band sebanyak 8 orang dan kelompok kedua latihan ladder sebanyak 8 orang. Pengambilan data dilakukan dengan tes kecepatan lari sepanjang 60 meter di lapangan sepak bola Cibelok. Desain penelitian yang digunakan adalah pre-test and post-test group, oleh karena itu, pengambilan data dilakukan pada saat pretest dan posttest. Berdasarkan hasil perhitungan diperoleh peningkatan hasil kecepatan lari dengan latihan Resistance band sebesar 4,95\%, sedangkan dengan latihan Ladder sebesar 13,58\%. Sehingga latihan Ladder lebih efektif untuk meningkatkan kecepatan lari. Simpulan dari penelitian ini adalah metode latihan latihan Ladder lebih efektif dan baik dalam meningkatkan kecepatan lari pada pemain ekstrakulikuler futsal di SMAN 3 Pemalang.
\end{abstract}

Kata Kunci : Futsal, Kecepatan Lari, Resistance Band, Ladder 


\section{PENDAHULUAN}

Menurut Mikanda Rahmani (2014:1) Olahraga merupakan suatu aktivitas gerak tubuh, mulai dari anggota tubuh bagian atas dan bagian bawah. Dikatakan aktivitas karena memiliki tujuan pada akhirnya, yakni kualitas hidup yang meningkat, sehingga menjadikan tubuh menjadi menjadi sehat dan bugar. Aktivitas menyehatkan ini selain dijadikan aktivitas pengisi waktu luang, juga dapat diajdikan sebagai sarana untuk mengasah kemampuan diri dalam berolahraga atau wadah untuk menjadi atlet professional atau olahrag prestasi.

Futsal merupakan yang dimainkan oleh dua tim yang berlawanan. Hanya saja, dalam futsal setiap tim terdiri atas lima orang. Selain itu, futsal umumnya dimainkan dilapangan indoor atau ruangan. Olahrga yang satu ini merupakan salah satu olahraga populer di dunia. Masyarakat dari berbagai Negara sangat menggemari olahraga ini.Sejarah permainan futsal diciptakan pada tahun 1930 di Uruguay oleh Juan Carlos Ceriani. Dengan demikian, dapat dikatakan bahwa futsal merupakan cabang olahraga baru. Pada awalnya futsal dianggap sebagai permainan mini dari sepak bola. Hal ini dikarenakan teknik permainan dan aturan permainan hamper sama dengan sepak bola. (Mikanda Rahmani 2014:157)

Pengertian latihan menurut Tjalik Soegiarto pada tahun 2002 dalam bukunya Fisiologi latihan. Menurut Tjalik Soegiarto (2002: 4) pengertian latihan merupakan proses yang sistematis dari berlatih, yang dilakukan secara berulang-ulang dengan kian hari kian meningkat dengan metode yang memiliki tujuan. Pada prinsipnya latihan merupakan proses perubahan kearah yang lebih baik, yaitu meningkatkan kualitas fisik, kemampuan fungsional tubuh dan kualitas psikis seseorang.

Hasil tes tersebut dapat dijadikan masukan untuk memilih latihan mana yang lebih efektif dalam melakukan lari sprint. Berdasarkan uraian diatas maka penulis tertarik untuk mengadakan penelitian dengan judul "Perbandingan Latihan Resistance band Dan Ladder Untuk Meningkatkan Kecepatan Lari Terhdap Pemain Ekstrakulikuler Pemalang SMA N 3 Pemalang”.

\section{METODE}

Desain penelitian yang digunakan dalam penelitian ini adalah pre-test and post-test group. Suharsimi Arikunto, (2010:124) mengatakan pre-test adalah observasi yang dilakukan sebelum eksperimen dan post-test adalah observasi yang dilakukan sesudah eksperimen. Pre-test dapat memberikan landasan untuk membuat komparasi prestasi subjek yang sama sebelum dan sesudah dikenai perlakuan. Pada penelitian ini mengambil sampel siswa ekstrakulkuler futsal SMA N 3 Pemalang dengan jumlah sampel 16 siswa yang dibagi atas dua kelompok yang meliputi kelompok A diberikan latihan Resistance Band dan kelompok B. 
ISSN. 2775-4324 (Online)

Journal of Physical Activity and Sports

Volume 2, Nomor 2, Agustus 2021, 204-207

\section{HASIL DAN PEMBAHASAN}

A. HASIL

Tabel : Peningkatan Rata-Rata Kecepatan Lari

\begin{tabular}{|c|c|c|c|c|}
\hline Latihan & Data & Rata-Rata & Selisih & Peningkatan \\
\hline \multirow{2}{*}{ Resistance Band } & Pretest & 8,88 & \multirow{2}{*}{0,44} & $4,95 \%$ \\
\cline { 2 - 3 } & Posttest & 8,44 & & \\
\hline \multirow{2}{*}{ Ladder } & Pretest & 8,991 & \multirow{2}{*}{1,221} & $13,58 \%$ \\
\cline { 2 - 3 } & Posttest & 7,77 & & \\
\hline
\end{tabular}

Sumber : Data primer penelitian yang diolah (2021)

Berdasarkan hasil perhitungan pada Tabel 4.10, diperoleh peningkatan hasil kecepatan lari dengan latihan resistance band pada pemain ekstrakulikuler futsal di SMAN 3 Pemalang sebesar 4,95\%, sedangkan peningkatan hasil kecepatan lari dengan latihan ladder pada pemain ekstrakulikuler futsal di SMAN 3 Pemalang sebesar 13,58\%. Karena peningkatan rata-rata kecepatan lari lebih tinggi menggunakan latihan ladder dibandingkan latihan resistance band maka dapat disimpulkan bahwa latihan ladder lebih efektif dan baik dalam meningkatkan kecepatan lari pada pemain ektrakulikuler futsal di SMAN 3 Pemalang.

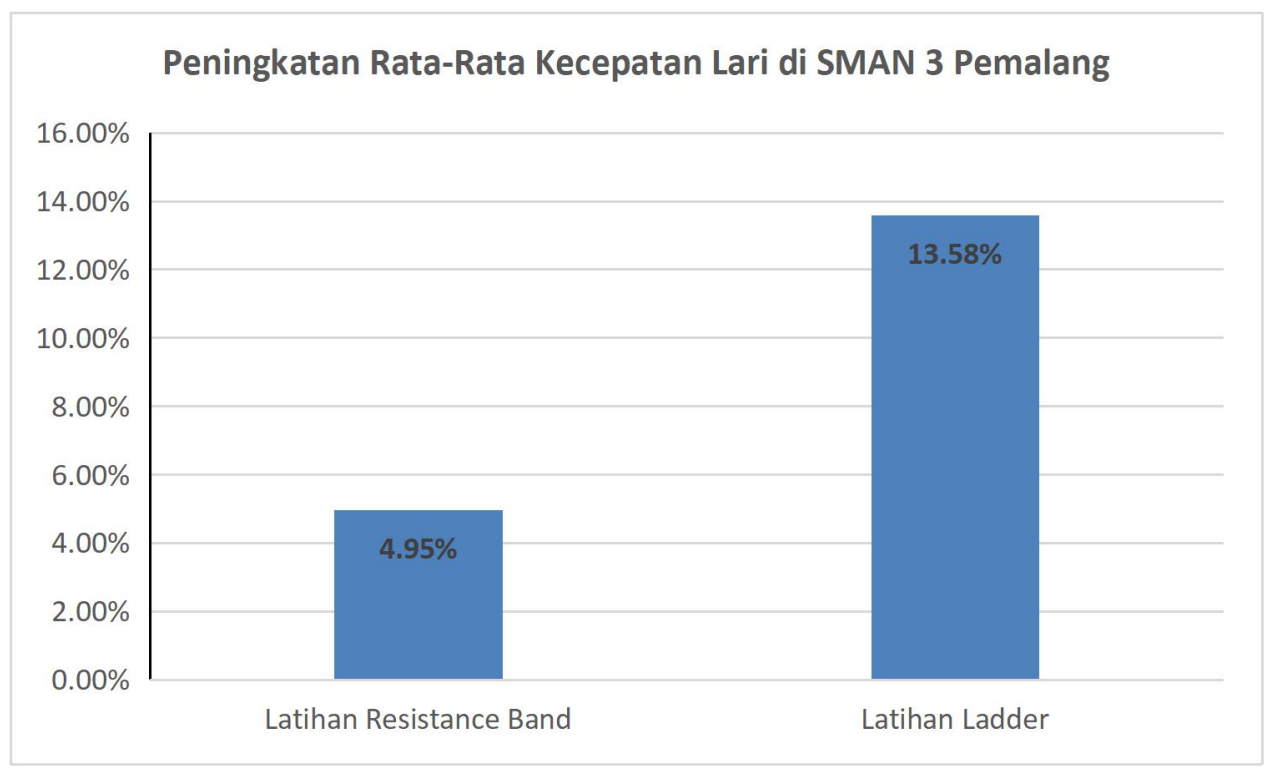

Gambar Grafik Peningkatan Rata-Rata Kecepatan Lari di SMAN 3 Pemalang 
Futsal Sma $N 3$ Pemalang

Liyalin Mubarok

\section{B. PEMBAHASAN}

Kecepatan merupakan salah satu aspek kemampuan yang diperlukan dalam cabang olahraga salah satunya yaitu futsal. Dalam studi kasus ini, peneliti melakukan penelitian untuk meningkatkan kecepatan lari pada pemain ekstrakulikuler futsal di SMAN 3 Pemalang dengan menerapkan latihan resistance band dan latihan ladder. Pengambilan data dilakukan pada saat pretest (sebelum diberikan latihan/treatment) dan posttest (setelah diberikan latihan/treatment) kecepatan lari 60 meter pada siswa di SMAN 3 Pemalang sebanyak 16 orang. Kelompok 1 sebanyak 8 orang diberikan latihan resistance band dan kelompok 2 sebanyak 8 orang diberikan latihan ladder.

\section{KESIMPULAN}

Berdasarkan hasil analisis data dan pembahasan maka hasil peneliti ini dapat disimpulkan sebagai berikut :

a. Ada pengaruh signifikan antara latihan Resistance band terhadap kecepatan lari pada pemain futsal ekstrakulikuler SMA N 3 Pemalang.

b. Ada pengaruh signifikan latihan Ladder terhadap keceptan lari pada pemain futsal ekstrakulikuler SMA N 3 Pemalang.

c. Ada perbedaan pengaruh signifikan antara latihan Resistance band dan Ladder terhadap kecepatan lari pada pemain futsal ekstrakulikuler SMA N 3 Pemalang.

d. Latihan menggunakan Ladder lebih baik dibandingkan dengan latihan Resistance band.

\section{DAFTAR PUSTAKA}

Moh Ali Ridho, 2017 PENGARUH LATIHAN DENGAN MENGGUNAKAN PARASUT TERHADAP KECEPATAN LARI $60 \mathrm{M}$ (STUDI EKSTRAKULIKULER ATLETIK SMP DR. SEOTOMO, USIA 13-15 TAHUN

Rahmani, Mikanda. 2014. Buku SUPER LENGKAP OLAHRAGA.Jakarta : Dunia Cerdas.

Sugiyono, 2015. Metode Penelitian Pendidikan. Bandung : Alfabeta

Suharmisi Arikunto,2010. Prosedur Penelitian. Bandung : Alfbeta

Tjalik Soegiarto, 2002. Fisiologi olahara. Yogyakarta : FIK UNY

Widyastuti. 2011. Tes dan Pengukuran Olahraga. Jakarta : PT Bumi Timur Jaya 